\title{
Assessment of Cardiac Involvement in Fabry Disease (FD) with Native T1 Mapping
}

\section{Natives T1-Mapping zur Beurteilung einer kardialen Beteiligung bei Morbus Fabry}

Authors

Fritz Christian Roller ${ }^{1}$, Sven Fuest ${ }^{2}$, Marco Meyer ${ }^{2}$, Sebastian Harth ${ }^{1}$, Dursun Gündüz ${ }^{3}$, Pascal Bauer ${ }^{3}$, Christian Schneider ${ }^{1}$, Arndt Rolfs ${ }^{4}$, Gabriele Anja Krombach ${ }^{1}$, Christian Tanislav ${ }^{2}$

Affiliations

1 Diagnostic and Interventional Radiology, Justus-LiebigUniversity, Giessen, Germany

2 Neurology, Justus-Liebig-University, Giessen, Germany

3 Angiology, Justus-Liebig-University, Giessen, Germany

4 Neurology, University-Hospital Rostock, Germany

Key words

cardiac, technical aspects, MR imaging

received 28.10.2017

accepted 16.01.2019

Bibliography

DOI https://doi.org/10.1055/a-0836-2723

Published online: 12.2 .2019

Fortschr Röntgenstr 2019; 191: 932-939

(c) Georg Thieme Verlag KG, Stuttgart · New York

ISSN 1438-9029

Correspondence

Dr. Fritz Christian Roller

Radiologie, Universitätsklinikum Giessen, Klinikstraße 36, 35392 Giessen, Germany

Tel.: ++49/641/98556329

Fax: ++49/641/98541809

fritz.c.roller@radiol.med.uni-giessen.de

\section{ZUSAMMENFASSUNG}

Ziel Morbus Fabry (FD) ist eine X-chromosomale Multiorganerkrankung des lysosomalen Metabolismus, wobei die kardiale Beteiligung die Haupttodesursache der Erkrankung darstellt. Deswegen ist es wichtig, möglichst frühe Erkrankungsmanifestationen zu detektieren, um einen maximalen therapeutischen Nutzen zu erzielen. Das Ziel unserer Studie war es, die Wertigkeit des nativen T1-Mappings als krankheitsspezifisches Äquivalent zu untersuchen.

Material und Methoden 16 konsekutive FD-Patienten (9 weiblich, 7 männlich; Altersmedian 54 Jahre; IQR 17) und 16 Kontrollpatienten ( 9 weiblich, 7 männlich; Altersmedian 52 Jahre, IQR 20) wurden mit einem 1,5-Tesla MRT-System untersucht. Das native T1-Mapping wurde als modifizierte Look-Locker-Sequenz (MOLLI) durchgeführt, die Messungen erfolgten im septalen linksventrikulären Myokard auf mittventrikulären Kurzachsenschnitten. Zudem wurden die linksventrikuläre Funktion und Morphologie, das Vorhandensein einer Kontrastmittelspätanreicherung sowie cTnl- und Lyso-Gb3Laborwerte ausgewertet.

Ergebnisse Die mediane native septale T1-Zeit bei FD-Patienten betrug 889,0 und 950,6 für die Kontrollgruppe $(p<0,003) .5(31,25 \%)$ Patienten hatten eine Kontrastmittelspätanreicherung und positive cTnl-Werte, 4 Patienten (25,0\%) eine linksventrikuläre Hypertrophie. Die 5 cTnl- und die 8 Lyso-Gb3-positiven Patienten hatten signifikant niedrigere native T1-Zeiten $(p<0,05$, respektive $p<0,01)$. Unter der Annahme eines Grenzwertes von 900 ms für die Detektion eines erhöhten, zellulären Lipidgehalts zeigten 9 Patienten (56,25\%) pathologische Werte. Davon waren 8 Patienten Lyso-Gb3- und 4 Patienten cTnl-positiv. Zudem zeigte sich eine gute negative Korrelation der nativen T1-Zeit zu den Lyso-Gb3-Werten $(r=-0,582 ; p=0,018)$.

Schlussfolgerung Offensichtlich reflektiert eine pathologische native T1-Zeit eine kardiale Beteiligung bei FD-Patienten. Zukünftig könnte natives T1-Mapping als Biomarker in der Bildgebung behilflich sein, frühe kardiale Beteiligungen im Rahmen des FD zu detektieren, bevor andere morphologische Veränderungen zu erkennen sind.

\section{Kernaussagen:}

- Die native T1-Zeit ist bei Patienten mit Morbus Fabry signifikant niedriger.

- Die native T1-Zeit korreliert zu kardialen und erkrankungsspezifischen Biomarkern.

- Das native T1-Mapping könnte großes Potenzial in Diagnostik und Therapie-Monitoring haben.

\section{ABSTRACT}

Purpose Fabry disease (FD) is an X-linked multi-organ disorder of lysosomal metabolism with cardiac disease being the leading cause of death. Identifying early FD-specific pathologies is important in the context of maximum therapeutic benefit in these stages. Therefore, the aim of this study was to investigate the value of quantitative cardiac T1 mapping as a potential disease-specific surrogate. 
Methods 16 consecutive FD patients ( 9 female, 7 male; median age: 54 years, IQR 17) and 16 control patients ( 9 female, 7 male; median age: 52 years, IQR 20) were investigated at 1.5 Tesla. Native T1 mapping was performed using a modified look locker inversion recovery sequence (MOLLI) and native T1 times were measured within the septal myocardium at the midventricular short-axis section. Also functional parameters, left ventricular morphology, presence of late-gadolinium enhancement, cTnl- and Lyso-Gb3-Levels were evaluated.

Results The median native septal T1 time for FD was $889.0 \mathrm{~ms}$ and $950.6 \mathrm{~ms}$ for controls $(\mathrm{p}<0.003)$. LGE and positive $\mathrm{CTnl}$ values $(0.26 \pm 0.21)$ were present in $5 \mathrm{FD}$ patients (31.25\%), and left ventricular hypertrophy (LVH) was present in $4 \mathrm{FD}$ patients $(25.00 \%)$. The $4 \mathrm{cTnl}$ and 8 Lyso-Gb3 positive FD patients had significantly lower native $T 1$ values $(p<0.05$, respectively $\mathrm{p}<0.01$ ). Assuming a T1 cut-off value of $900 \mathrm{~ms}$ for the identification of increased cardiac lipid deposit, 9 patients with FD (56.25\%) had pathologic values (4 patients cTnl and 8 patients Lyso-Gb3 positive). Moreover, native septal T1 showed a good negative correlation to Lyso-Gb3 $(r=-0.582 ; p=0.018)$.

Conclusion A pathologic cardiac native $\mathrm{T} 1$ time obviously reflects cardiac involvement in the scope of FD at tissue level. In the future native T1 mapping as an imaging biomarker might allow identification of early stages of cardiac involvement in FD before morphological changes are obvious.

\section{Key Points:}

- Native T1 values are significantly decreased in Fabry disease.

- Native T1 shows promising correlation to cardiac and Fabry-specific biomarkers.

- Native T1 mapping might have great potential for early disease detection and therapy monitoring.

\section{Citation Format}

- Roller FC, Fuest S, Meyer M et al. Assessment of Cardiac Involvement in Fabry Disease (FD) with Native T1 Mapping. Fortschr Röntgenstr 2019; 191: 932-939

\section{Introduction}

Fabry disease (FD) is an X-linked disorder of lysosomal metabolism with inability to catabolize glycosphingolipids due to a deficiency of the enzyme alpha-galactosidase [1]. It is a multisystem disorder and glycosphingolipids accumulate in many organs including the skin, myocardium and kidneys. Male homozygotes are more affected by the disease, which presents in adolescence with burning extremity pain (acroparesthesia) and progressive multi-organ failure [2].

FD can cause left ventricular hypertrophy (LVH) due to storage of glycosphingolipid in myocytes, valves and vascular endothelium [3]. Cardiac decompensation is triggered by myocardial fibrosis and is usually more extensive in men than in affected women $[1,4]$. Proving heart involvement in FD cardiac magnetic resonance imaging (CMRI) is well established [5]. Beside nonspecific signs, like LVH and reduced left ventricular function, basal infero-lateral late gadolinium enhancement (LGE) without affecting the endocardium is a characteristic hallmark of cardiac FD manifestation [5]. The evidence of LGE also possesses a prognostic relevance. Once demonstrated, a lack of response to enzyme replacement therapy could be expected, which might be due to irreversible tissue damage with the development of fibrosis [5]. However, LGE as a surrogate is limited due to its dichotomous character. Its presence requires at least $15 \%$ focal matrix expansion [6]. Stages prior to the development of fibrosis still remain hidden by investigating LGE. Identifying early cardiac changes at the tissue level requires other approaches. Assessment of myocardial lipid deposition by localized $1 \mathrm{H}$ magnetic resonance spectroscopy (1H-MRS) seems a suitable and time-efficient alternative [7] for the noninvasive assessment of myocardial lipid content [7-10] as several studies at 1.5 Tesla showed. A recent study by Petritsch et al. performed at 3.0 Tesla concluded that a comprehensive cardiac examination protocol in FD patients should include LGE imaging, 1H-MRS and native T1 mapping [11], which also seems to be a promising increment, as it allows the quantification of myocardial T1 times on a pixelwise basis (parametric imaging). Some previous case series indicated the potential benefit of native T1 mapping for identifying early stages of the disease $[12,13]$. This is of great relevance as the early establishment of enzyme replacement therapy is associated with maximum benefit [14]. Therefore, we aimed to assess cardiac native T1 mapping in FD in the present case-control study and correlate the findings with the presence of LGE, LVH and biomarkers such as cardiac troponin I (cTnl) and lyso-globotriaosylceramide (Lyso-Gb3) [15-17].

\section{Methods}

\section{Study design}

In case-control design we included 16 patients with FD and 16 healthy volunteers in our study. Matching criteria were age and sex. In all patients the diagnosis of FD was proved by molecular genetic analysis verifying a heterozygous or homozygous mutation in the $\alpha$-GAL-A-gene [15]. All patients and individuals in the control group underwent cardiac MRI. Contraindications for cardiac MRI and exclusion criteria were renal failure (glomerular filtration rate below $30 \mathrm{ml} / \mathrm{min} / 1.73 \mathrm{~m}^{2}$ ), incompatible cochlear or metallic implants, known gadolinium intolerance, claustrophobia, or the inability to lie supine for the duration of the protocol due to dyspnea. In controls cardiac disease was ruled out by follow-up and by validation and consultation of a cardiologist. The study protocol was reviewed and approved by the local ethical committee. 


\section{CMR imaging}

Cardiac imaging was performed with a 1.5 Tesla MRI scanner (Somatom Avanto, Siemens Healthcare, Forchheim, Germany) using an eight-element phased array cardiac coil. An appropriate CMR protocol containing thoracic survey images (in axial, coronal, and sagittal orientation), steady-state-free precession (SSFP) CINE sequences aligned to 2-, 3- and 4-chamber view (CV), and shortaxis (SA) obtained during breath-hold, black-blood imaging (T2 turbo spin echo), late gadolinium enhancement imaging (LGE; T1 gradient echo with inversion recovery) and native T1 mapping was used as previously described [18]. Gadobenate dimeglumine (Gd-BOPTA; Multihance, BRACCO Imaging) was injected at a dose of $0.1 \mathrm{mmol} / \mathrm{kg}$ and LGE imaging was performed 12 minutes after contrast agent injection. For the assessment of left ventricular (LV) function, the absolute LV volume was calculated on end-diastolic and end-systolic short-axis CINE images. The endocardial contours were drawn manually with exclusion of the papillary muscles and trabeculae from the LV cavity. Ventricular volume was estimated using the Simpson rule and EF was calculated as (end-diastolic volume (EDV) - end-systolic volume (ESV)/end-diastolic volume (EDV)). The end-systolic and end-diastolic diameter (ESD and EDD) were measured at the basal short-axis level. Argus software package (Siemens Syngo MMWP Version VE40A, Siemens Healthcare, Forchheim, Germany) was used for post-processing.

Native T1 maps were acquired at the basal, mid-ventricular, and apical short-axis sections with a modified Look-Locker inversion-recovery (MOLLI) sequence, with three images in the first two Look-Locker segments and five images for the third inversion (known as the "3-3-5" standard protocol; 11 images during 17 heartbeats) and maps were generated after in-line motion correction [19].

The imaging parameters were: slice thickness: $8 \mathrm{~mm}$; spatial resolution: $2.2 \mathrm{~mm} \times 1.8 \mathrm{~mm} \times 8 \mathrm{~mm}$; $6 / 8$ partial Fourier acquisition; field of view: $240 \times 340 \mathrm{~mm}$; matrix: $192 \times 124$; flip angle 35 ; TR 740 and TE 1.06; TI $100 \mathrm{~ms}$ and TI Increment 80 ms; trigger delay: $300 \mathrm{~ms}$; inversions 3; acquisition heartbeats: 3-3-5; scan time: 17 heartbeats.

\section{Qualitative and quantitative image assessment}

The original generated images were assessed for artifacts caused by susceptibility, cardiac, diaphragmatic, or respiratory motion. Each motion-corrected series was evaluated for correct image alignment, and each T1 map was carefully checked for signal loss due to misalignment and motion [18].

\section{Measurement of native T1}

Native myocardial T1 measurements were performed in regions of interest (ROI) at the midventricular SA section (septum and the left ventricular free wall). Myocardial border areas - areas between the myocardium and blood pool - were excluded to avoid partial volume averaging artifacts and registration errors with gradual T1 value changes. To exclude size-dependent differences of native $\mathrm{T} 1$ values between the FD patients and the control group, the ROI sizes were also evaluated. All native T1 measurements were performed in agreement by two radiologists with experience in cardiac imaging (G.K./18 years of experience; F.R./7 years of experience). Both radiologists performed the measurements blinded to patient demographics. Moreover, assessment of LGE was performed blinded to native T1 maps and CINE images and vice versa. All T1 maps were of diagnostic quality and sufficient myocardial T1 measurements were reliably performed in all patients.

\section{Laboratory assessment}

Laboratory assessment was performed as previously described [20]. A sensitive immunoassay (ADVIA Centaur ${ }^{\circledR}$ TnI-Ultra ${ }^{\mathrm{TM}}$ immunoassay, Siemens Medical Solutions Diagnostics, Tarrytown, NY, USA), which fulfills the criteria mandated by the European Society of Cardiology and the American College of Cardiology, was used to measure cTnl values in plasma. As reported in the package leaflet, the imprecision of the immunoassay depends on the $c T n l$ concentrations with a variation coefficient of $10 \%$ at $0.03 \mathrm{ng} / \mathrm{ml}$ and a variation coefficient $\leq 10 \%$ for cTnl concentrations $\geq 0.04 \mathrm{ng} / \mathrm{ml}$. As recommended, a cTnl level of $0.04 \mathrm{ng} / \mathrm{ml}$ $\left(99^{\text {th }}\right.$ percentile of healthy volunteers) was used as the clinical decision limit to rule out acute myocardial infarction. The test was calibrated to measure $c T n l$ values $\geq 0.01 \mathrm{ng} / \mathrm{ml}$ (the lower detection limit of the immunoassay is $0.006 \mathrm{ng} / \mathrm{ml}$ ) in our study. Therefore, we defined cTnl levels as follows: cTnl levels $<0.01 \mathrm{ng} / \mathrm{ml}$ were defined as subnormal, cTnl levels $\geq 0.01 \mathrm{ng} / \mathrm{ml}$ and $<0.04 \mathrm{ng} / \mathrm{ml}$ were defined as normal, and cTnl levels $\geq 0.04 \mathrm{ng} / \mathrm{ml}$ were defined as elevated. Lyso-Gb3 was measured in serum and values $>1.0 \mathrm{ng} / \mathrm{ml}$ were interpreted as elevated. All Lyso-Gb3 measurements were performed the Centogene AG (Rostock; Germany).

\section{Statistical analysis}

SPSS statistical software version 20 (SPSS, Chicago, III) was used for statistical analysis. Patient characteristics were described by mean \pm standard deviation (SD) and median with interquartile ratio (IQR). Data was tested for normal distribution using the Shapiro-Wilk test. The Student's t-test was used for data following normal distribution, and the Wilcoxon signed rank test (non-parametric test) was used for data not following normal distribution. Correlation strengths were tested using the Pearson correlation coefficient. Intra- and interobserver variability was tested with linear regression analysis and Bland-Altman plots. An alpha error of less than 0.05 was accepted as statistically significant.

\section{Results}

Cardiac function ( $\vee$ Table 1 ): Both the FD patients and the healthy controls showed normal left heart function. The median left ventricular ejection fraction (EF) was $64.5 \%$ (IQR 9.8) for FD patients and $66.3 \%$ (IQR 8.2) for healthy controls. Also the mean end-diastolic volume (EDV), end-systolic volume (ESV), stroke volume (SV), end-diastolic (EDD) and end-systolic diameters (ESD) revealed normal values for both groups. $\mathrm{LVH}$, defined as a septal myocardial diameter $\geq 13 \mathrm{~mm}$, was present in $4 \mathrm{FD}$ patients 
- Table 1 Cardiac function and LGE.

- Tab. 1 Kardiale Funktion und Kontrastmittelspätanreicherung.

\begin{tabular}{|c|c|c|c|c|c|c|c|}
\hline & $\begin{array}{l}\text { FD } \\
n=16\end{array}$ & Q25 & Q75 & $\begin{array}{l}\text { controls } \\
n=16\end{array}$ & Q25 & Q75 & $\mathbf{p}$ \\
\hline function: & \multicolumn{3}{|l|}{ median (IQR) } & \multicolumn{4}{|l|}{ median (IQR) } \\
\hline $\mathrm{EF}(\%)$ & $64.5(9.8)$ & 60.0 & 69.8 & $66.3(8.20)$ & 62.1 & 70.3 & 0.61 \\
\hline $\mathrm{EDV}(\mathrm{ml})$ & $125.5(25.8)$ & 112.5 & 138.3 & $121.9(24.4)$ & 115.5 & 139.9 & 0.35 \\
\hline ESV (ml) & $45(22.8)$ & 31.8 & 54.5 & $42.5(23.1)$ & 33.6 & 56.1 & 0.55 \\
\hline SV (ml) & $80.5(15.8)$ & 73.8 & 89.5 & $83.5(17.0)$ & 76.0 & 93.0 & 0.59 \\
\hline \multicolumn{8}{|c|}{ diameters: (mm) } \\
\hline Septum & $9(4.0)$ & 7.8 & 11.8 & $8.5(2.0)$ & 7.7 & 9.7 & 0.19 \\
\hline Lateral wall & $7(3.3)$ & 6.5 & 9.8 & $5.9(0.9)$ & 5.5 & 6.4 & 0.09 \\
\hline EDD & $45.5(7.5)$ & 42.8 & 50.3 & $48.5(6.0)$ & 45.4 & 51.4 & 0.44 \\
\hline ESD & $28.5(8.3)$ & 25.7 & 34.0 & $28.5(4.1)$ & 26.3 & 30.4 & 0.67 \\
\hline \multirow[t]{2}{*}{ LGE } & n (\%) & & & n (\%) & & & \\
\hline & $5(31.25)$ & & & 0 & & & \\
\hline
\end{tabular}

FD - Fabry disease, EF - ejection fraction, EDV - enddiastolic volume, ESV - endsystolic volume, SV - stroke volume, EDD - enddiastolic diameter, ESD - endsystolic diameter, LGE - late gadolinium enhancement, IQR - interquartile ratio, Q25 $-25^{\text {th }}$ quartile, Q75 $-75^{\text {th }}$ quartile.

> Table 2 Native T1 mapping: FD versus control subjects.

- Tab. 2 Natives T1-Mapping: Morbus Fabry vs. Kontrollpatienten.

\begin{tabular}{|c|c|c|c|c|c|c|c|}
\hline & FD & & & Controls & & & $\mathbf{p}$ \\
\hline native T1: (ms) & median (IQR) & Q25 & Q75 & median (IQR) & Q25 & Q75 & \\
\hline Septal & $889.0(76.8)$ & 877.5 & 954.3 & $950.0(34.3)$ & 941.3 & 975.6 & $<0.03$ \\
\hline Lateral wall & $925.0(43.8)$ & 910.0 & 953.8 & $960.0(29.3)$ & 949.6 & 978.9 & 0.09 \\
\hline Scar area & $954.0(33.8)$ & 941.2 & 975.0 & - & & & \\
\hline
\end{tabular}

$(25.0 \%)$ and in none of the control group patients. The median septal myocardial diameter was 9.0 (IQR 4.0) mm for FD patients and 8.5 (IQR 2.0) for controls ( $p=0.19)$.

Native T1 time: The median septal T1 time for FD patients was $889.0 \mathrm{~ms}(\mathrm{IQR} 76.8)$ and was lower $(\mathrm{p}<0.03)$ compared to the controls with a median septal T1 time of $950.0 \mathrm{~ms}$ (IQR 22.0). The median T1 time of the left ventricular free wall (lateral wall) was $925.0 \mathrm{~ms}$ (IQR 43.8) for FD patients and $960.0 \mathrm{~ms}$ (IQR 29.3) for the control subjects $(p<0.09)$. LGE at the infero-lateral wall was present in $5 \mathrm{FD}$ patients $(31.25 \%)$ and in none of the control group subjects. The median native T1 time in the LGE affected areas was $954.0 \mathrm{~ms}$ (IQR 33.8) for the FD patients. The results are presented in $>$ Table $\mathbf{2}$ and in $>$ Fig. 1. Moreover, the FD patients with LVH showed reduced septal T1 times with a median native T1 time of $884.0 \mathrm{~ms}$ (IQR 26.8) compared to the FD patients without LVH ( $\vee$ Table 3 ). $>$ Fig. 2 a, $\mathbf{b}$ shows the native
T1 map and LGE image of a 52-year-old male FD patient with LGE at the inferolateral wall, LVH and reduced septal native T1 times and Fig. $\mathbf{3 a}$, $\mathbf{b}$ shows the native T1 map and LGE image of a 27-year-old male FD patient without LGE, or LVH but reduced septal native $\mathrm{T} 1$ times.

Correlation between native T1 time and CTni: 5 of 16 FD patients (31.25\%) were cTnl positive (median cTnl 0.01; IQR $0.01)$. cTnl positive FD patients had significantly reduced median septal native T1 times with 880.0 ms (IQR 68.0) compared to cTnl negative FD patients with 948.0 ms (IQR 84.0) $(p<0.05)$. Moreover, a moderate negative correlation between $\mathrm{cTnl}$ and native T1 was present for the $c T n l$ positive FD patients $(r=-0.442$; $\mathrm{p}=0.086)$ as presented in $\triangleright$ Fig. 4 .

Correlation between native T1 time and Lyso-Gb3: The median Lyso-Gb3 level of the FD patients was $5.5 \mathrm{ng} / \mathrm{ml}$ (IQR 19.2). Lyso-Gb3 positive FD patients had significantly reduced median 
- Table 3 Native T1 mapping in FD.

- Tab.3 Natives T1-Mapping bei Patienten mit Morbus Fabry.

\begin{tabular}{|c|c|c|c|c|c|c|c|}
\hline & $\begin{array}{l}\text { LVH + } \\
n=4\end{array}$ & & & $\begin{array}{l}\text { LVH - } \\
\mathrm{n}=12\end{array}$ & & & P \\
\hline & median (IQR) & Q25 & Q75 & median (IQR) & Q25 & Q75 & \\
\hline \multirow[t]{2}{*}{ native $\mathrm{T1}$ (ms) } & $884.0(26.8)$ & 862.8 & 888.5 & $931.0(85.5)$ & 877.5 & 963.0 & 0.2214 \\
\hline & $\begin{array}{l}\text { cTnl + } \\
n=5\end{array}$ & & & $\begin{array}{l}\text { cTnl - } \\
n=11\end{array}$ & & & $\mathrm{p}$ \\
\hline \multirow[t]{2}{*}{ native T1 (ms) } & $880.0(68.0)$ & 820.0 & 888.0 & $948.0(84.0)$ & 881.0 & 965.0 & 0.048 \\
\hline & $\begin{array}{l}\text { Lyso-Gb3 + } \\
n=9\end{array}$ & & & $\begin{array}{l}\text { Lyso-Gb3 - } \\
n=7\end{array}$ & & & $\mathrm{P}$ \\
\hline native T1 (ms) & $880.0(35.0)$ & 853.0 & 888.0 & $961.0(40.0)$ & 933.0 & 973.0 & 0.0036 \\
\hline
\end{tabular}

LVH - left ventricular hypertrophy, IQR - interquartile ratio, Q25 $-25^{\text {th }}$ quartile, Q75 $-75^{\text {th }}$ quartile.

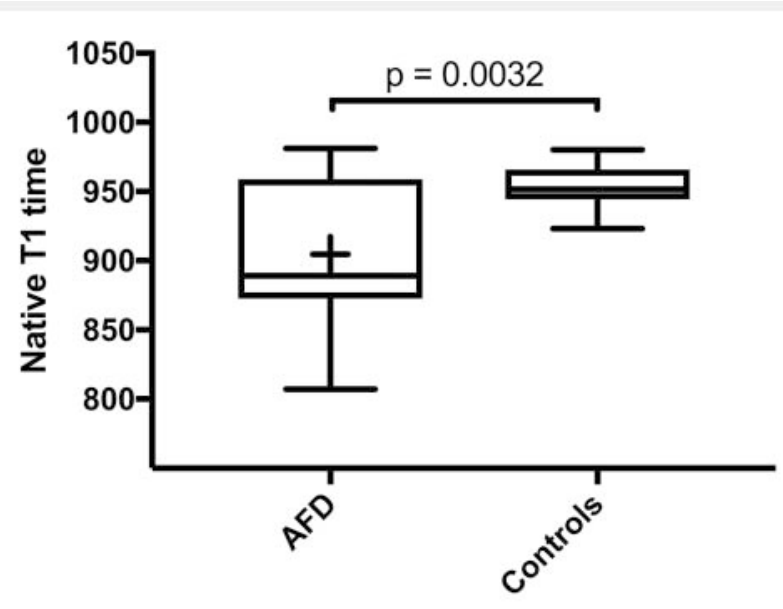

- Fig. 1 The box plot presents the septal native T1 times for FD patient and controls.

- Abb. 1 Der Boxplot zeigt die gemessenen septalen nativen T1Zeiten für Morbus-Fabry-Patienten und das Kontrollkollektiv.

septal native T1 times with 880.0 ms (IQR 35.0) compared to Lyso-Gb3 negative FD patients with $961.0 \mathrm{~ms}$ (IQR 40.0) $(p=0.0036)$. Compared to $c T n l$, a better moderate negative correlation between Lyso-Gb3 and native septal T1 was present $(r=-0.582 ; p<0.02)$ as shown in > Fig. 5.

Cut-off-value: Assuming a cut-off value of $900 \mathrm{~ms}$, which is more than 3 SD below the mean native septal T1 time of the healthy controls (952.6 ms $\pm 16.7 \mathrm{SD}$ ), for identification of cardiac FD involvement, 9 of 16 FD patients (56.25\%) revealed pathologic native septal T1 times. The cTnl level was increased in only 4 of these patients (44.44\%), while the Lyso-Gb3 level was increased in 8 (88.88\%). Interestingly, $3 \mathrm{FD}$ patients (18.75\%) without the presence of LVH, LGE and CTnl increase showed a significant native septal T1 time de-

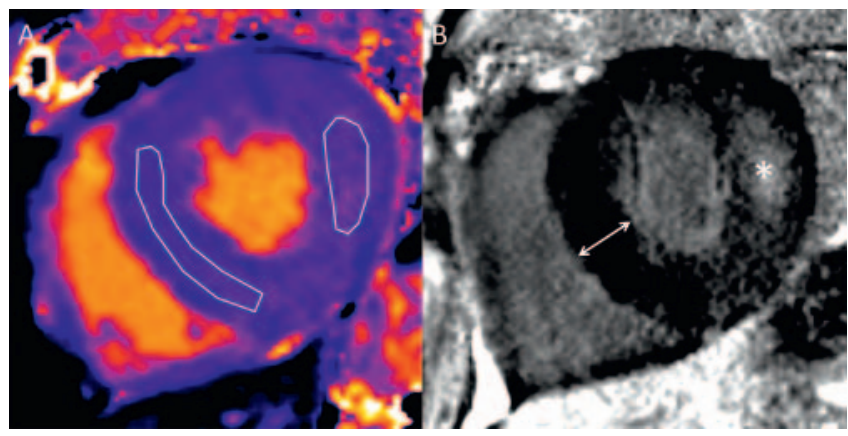

- Fig. 2 Native T1 map A and LGE image B of a 52-year-old male FD patient. Typical LGE is at the inferolateral wall (white asterisk), and also a significant LVH with a septal diameter of $20 \mathrm{~mm}$ is present (white two-sided arrow). The measured septal native $\mathrm{T} 1$ time within in the region of interest is $888 \mathrm{~ms}$, which is reduced, and the measured native $\mathrm{T} 1$ time within the scar area is $954 \mathrm{~ms}$, which is normal.

- Abb.2 Die Abbildung zeigt die native T1-Map A und das Bild der Kontrastmittelspätanreicherung B auf mittventrikulären Kurzachsenschnitten bei einem 52 Jahre alten männlichen Patienten mit Morbus Fabry. An der Inferolateralwand zeigt sich eine typische Kontrastmittelspätanreicherung (weißer Stern), zudem besteht eine deutliche septale linksventrikuläre Hypertrophie mit $20 \mathrm{~mm}$ (weißer Pfeil). Die im septalen Myokard innerhalb der Region von Interesse gemessene native T1-Zeit beträgt $888 \mathrm{~ms}$ (reduziert) und die innerhalb der Lateralwand im Narbenareal gemessene native T1-Zeit beträgt $954 \mathrm{~ms}$ (normal).

crease (values between $853 \mathrm{~ms}$ and $882 \mathrm{~ms}$ ) but increased Lyso-Gb3 level (median: 24.1, IQR 44.15; range: 5.60 to 93.9).

\section{Discussion}

In patients with FD, we detected lower values for native T1 times as compared to controls, indicating potential lipid storage at the tissue level. Lower values for native T1 times were especially pronounced in the ventricular septum. This might represent a 


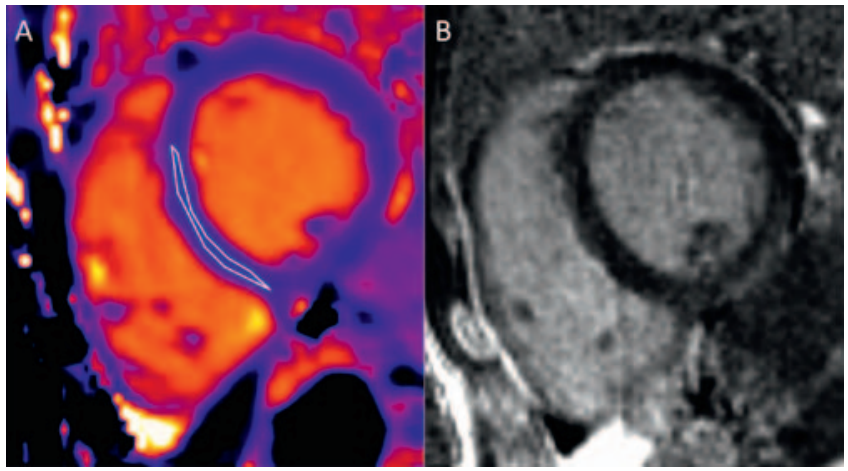

- Fig. 3 Native T1 map A and LGE image $\mathbf{B}$ at midventricular short axis of a 27-year-old male FD patient without LGE, LVH but reduced septal native $\mathrm{T} 1$ times. The measured septal native $\mathrm{T} 1$ time within the region of interest is $872 \mathrm{~ms}$.

- Abb. 3 Die Abbildung zeigt die native T1-Map A und das Bild der Kontrastmittelspätanreicherung B auf mittventrikulären Kurzachsenschnitten bei einem 27 Jahre alten männlichen Patienten ohne Nachweis einer Kontrastmittelspätanreicherung und linksventrikulärer Hypertrophie, aber mit dem Nachweis einer reduzierten septalen nativen T1-Zeit. Innerhalb der Region von Interesse im septalen Myokard beträgt die native T1-Zeit 872 ms.

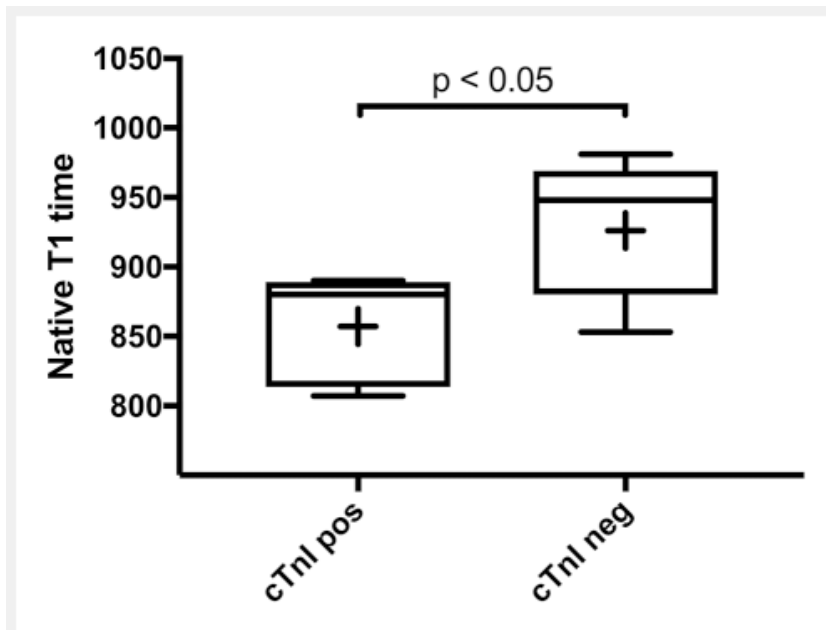

- Fig. 4 The box plot presents the native septal T1 times measured in cTNI positive and cTNI negative FD subjects.

- Abb. 4 Der Boxplot veranschaulicht die nativen septalen T1-Zeiten der cTnl-positiven und -negativen Morbus-Fabry-Patienten.

disease-specific finding, as far as the underlying pathological mechanism in FD is based on intracellular storage of sphingolipids [3]. Lower values for native T1 times in FD patients correlated with the presence of the cardiac biomarker cTnl as well as with elevated levels for Lyso-Gb3, the specific biomarker for FD, indicating the burden of disease [21]. In 4 FD patients with regular cardiac findings (no evidence of LVH, LGE or elevated cTnI), pathological native $T 1$ values were detected, potentially indicating an early stage of the disease; this could also be supported by elevated Lyso-Gb3 values detected in these patients, which might rule out a silent stage of FD.

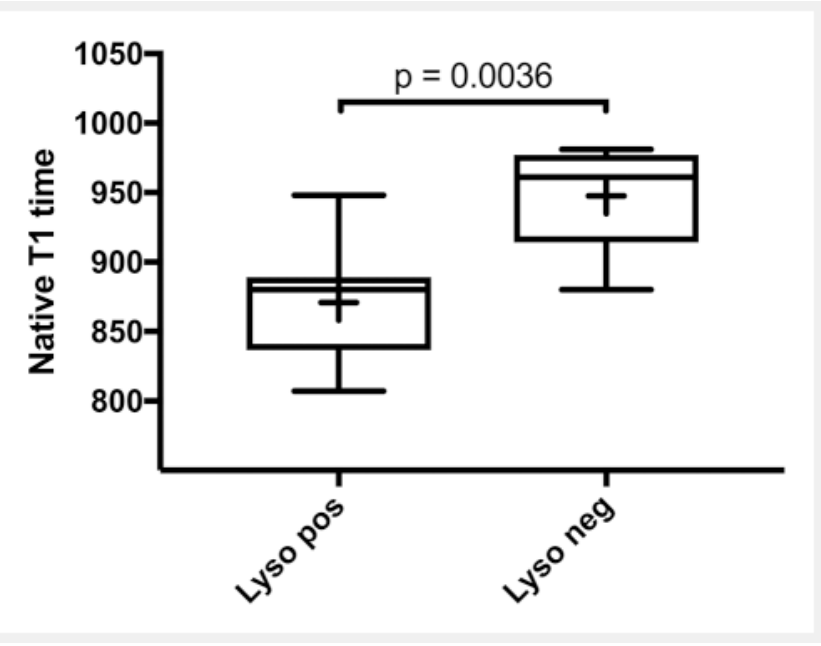

- Fig. 5 The box plot presents the septal native T1 times measured in Lyso-Gb3 positive and Lyso-Gb3 negative FD subjects.

- Abb. 5 Der Boxplot veranschaulicht die nativen septalen T1-Zeiten der Lyso-Gb3-positiven und -negativen Morbus-Fabry-Patienten.

In line with our findings, previous investigations also demonstrated lower values for native T1 times in patients with FD and cardiac involvement $[12,13]$. Sato and coworkers showed that by applying cardiac MRI, native T1 times were even useful to discriminate between cardiac involvement in FD and other pathologies with cardiac LVH [13]. In a further study the investigators could emphasize pathologic native $\mathrm{T} 1$ values as one of the most important findings, indicating cardiac involvement in FD irrespective of sex and cardiac morphology und function [13].

In our investigations we added information on important biomarkers, specific to the disease such as Lyso-Gb3 and specific to cardiac damage such as cTnl. Dichotomizing FD patients according to cTnl elevation versus none showed that the patients with increased levels had lower native T1 time values. Even a moderate correlation between the degree of cTnl elevation and native T1 time was obvious. In the context of new evidence for the relevance of a cTnl elevation in FD as an early indicator of cardiac involvement [22], our findings support the hypothesis that lower native T1 times might also serve as an early surrogate indicating deposition of lipids, which is one of the first steps in the pathophysiology of FD. It might indicate directly the pathology of FD at the tissue level. In this context it needs to be taken into account that biomarkers might reliably indicate tissue damage. However, they are not measurable until a systematic release and furthermore other conditions with direct cardiac tissue damage could also induce their secretion. Especially the secretion of cTnl was demonstrated in several other disorders with no direct cardiac pathology for example in lung embolism [23]. In one of our FD patients we found no evidence of cardiac involvement regarding the morphology (echocardiography, standard MRI), electrophysiology (ECG, Holter-ECG) and also no elevation in serial cTnl measurements, but we did find pathologically reduced native $\mathrm{T} 1$ times as an indicator of tissue deposition of lipids as an indication of early cardiac pathol- 


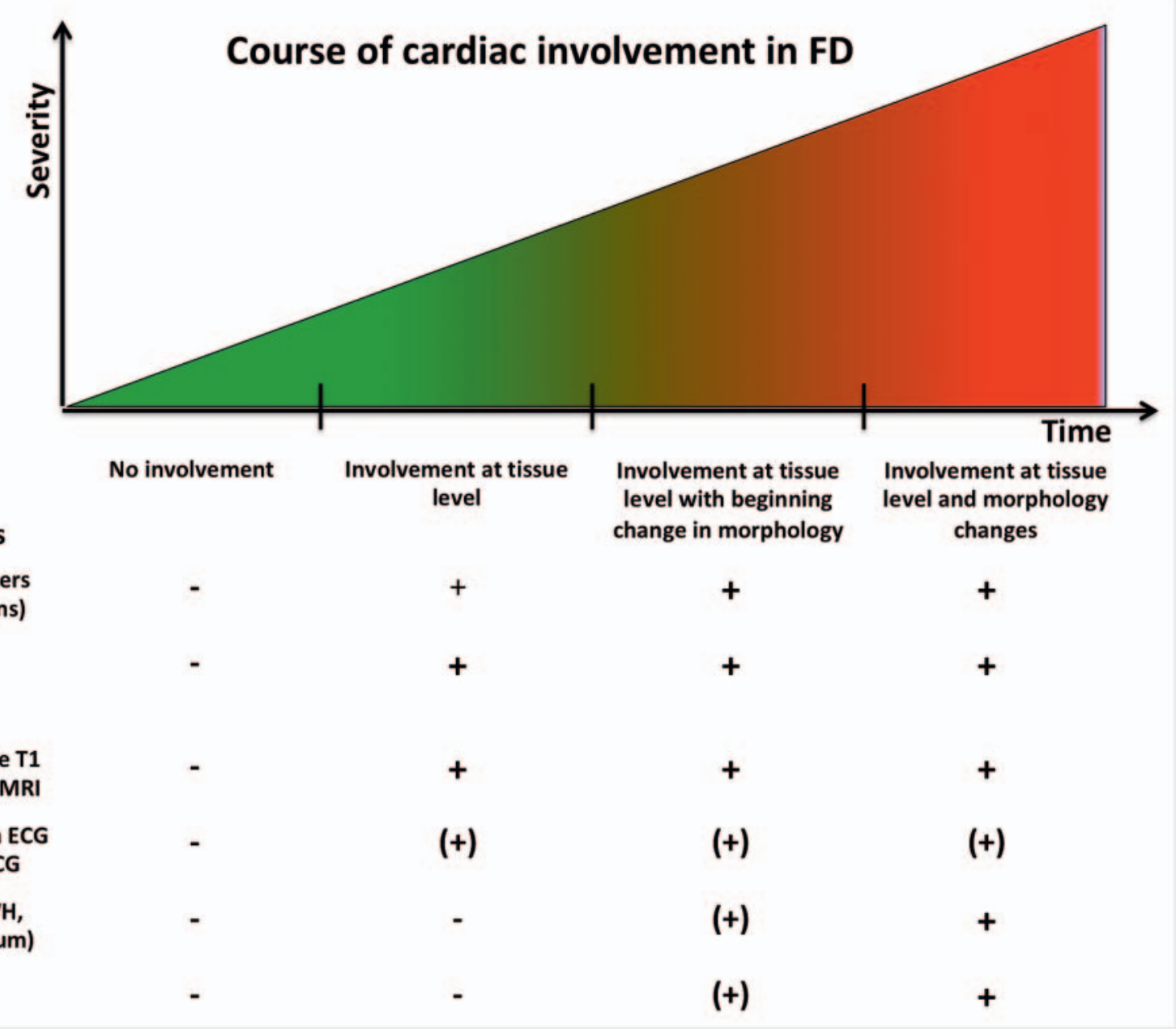

- Fig. 6 The course of cardiac involvement in FD. In the stage without cardiac involvement, no pathological findings are evident. In the first stage with the beginning of sphingolipid accumulation especially pathological findings of native $\mathrm{T} 1$ times and pathologic measures in $1 \mathrm{H}-\mathrm{MRS}$ and phosphor spectroscopy could be demonstrated. At this stage also specific cardiac biomarkers such as cardiac troponins could be measured. In the second stage beginning changes of heart morphology occur, such as hypertrophy (left ventricular hypertrophy (LVH) or increase in thickness of the ventricular septum) as well as evidence of fibrosis (in form of late gadolinium enhancement (LGE) are detectable. In the third stage morphological heart changes (LVH and/or LGE) and/or findings indicating involvement at the tissue level (pathological for native T1 times in the cardiac MRI and/or elevated cardiac biomarkers) are evident. At any stage ECG and/or Holter-ECG abnormalities could be detected.

- Abb. 6 Die Abbildung zeigt den zeitlichen Verlauf einer kardialen Beteiligung bei Morbus Fabry. In der ersten Phase der Erkrankung lassen sich keine kardialen Pathologien nachweisen. In der zweiten Phase lassen sich, hervorgerufen durch eine Akkumulation von Sphingolipiden, reduzierte native T1-Zeiten im Myokard messen und Veränderungen mittels 1H-MR- und Phosphor-Spektroskopie feststellen. Zudem können in dieser Phase pathologische Werte spezifischer kardialer Biomarker (Troponine) vorliegen. In der dritten Phase lassen sich zudem nun morphologische kardiale Veränderungen, wie beginnende linksventrikuläre Hypertrophie oder auch Fibrose (im Rahmen der Kontrastmittelspätanreicherung), nachweisen. In der letzten Phase lassen sich sowohl sichere morphologische kardiale Veränderungen und auch kardiale Veränderungen auf zellulärer Ebene nachweisen (pathologische native T1-Zeiten und/oder kardiale Biomarker). Grundsätzlich können sich in jeder Phase der Erkrankung pathologische EKG- bzw. Langzeit-EKG-Veränderungen zeigen.

ogy in FD. In this patient a silent stage of the disease could be ruled out by proteinuria and a markedly elevated Lyso-Gb3 value of $93.90 \mathrm{ng} / \mathrm{ml}$. This demonstrates that pathological native T1 times indicate cardiac involvement in FD at the tissue level, obviously prior to secretion of the biomarker cTnl. In a pathophysiological algorithm of a cardiac manifestation in $\mathrm{FD}$, a pathologically reduced native $\mathrm{T} 1$ time is obviously the first pathological finding beside pathologic measures in $1 \mathrm{H}-\mathrm{MRS}$ and phosphor spectroscopy indicating the disease, followed by the secretion of the cardiac biomar- ker cTnl. It is of particular relevance to consider these parameters in the diagnostic workup of FD, as greater benefit is expected when therapy is initiated at the stage in which these findings occurred, i. e., isolated without morphological changes. In the case of an ongoing process with the development of fibrosis and/or hypertrophy of the myocardium (LVH or LGE), limited therapeutic effects can be expected $[24,25]$. As in the early stages of cardiac FD with only pathological native T1 times and/or biomarker elevations, structural damage at the tissue level of the heart is already obvious. This 
finding should be considered and interpreted accordingly. In line with other investigations at this stage, irregular ECG and/or HolterECG findings could potentially be detected [26]. The course of cardiac involvement in FD and potential findings in the different diagnostic procedures are summarized in $>$ Fig. 6 .

The main limitation of our investigation is the small number of patients. However, as a proof of principle, our findings might serve as a starting point for further investigations evaluating the value of native cardiac T1 mapping in the course of cardiac pathology in FD.

\section{Conclusion}

In our case-control study we could demonstrate lower native cardiac T1 times in patients with FD in comparison to healthy controls. In some of the cases pathological native T1 times were detected without any pathological findings regarding the heart morphology and even without elevation of the specific cardiac biomarker cTnl. Cardiac MRI including native T1 mapping might therefore be useful for the detection of cardiac involvement at the tissue level, which might be relevant in the early stage of the disease.

\section{CLINICAL RELEVANCE OF THE STUDY}

- Cardiac MRI is frequently used in the diagnostic cascade of Fabry disease.

- Native T1 mapping within cardiac MRI for the detection of Fabry disease involvement is superior to left ventricular hypertrophy and LGE imaging.

- Native T1 mapping might also enable therapy monitoring of cardiac involvement in Fabry disease in the future.

\section{Conflict of Interest}

The authors declare that they have no conflict of interest.

\section{References}

[1] MacDermot KD, Holmes A, Miners AH. Anderson-Fabry disease: clinicalmanifestations and impact of disease in a cohort of 98 hemizygous males. J Med Genet 2001; 38: 750e60

[2] Hoey ET, Neil-Gallagher E. Utility of gadolinium enhancedcardiovascular MRI to differentiate Fabry's disease from other causes of hypertrophic cardiomyopathy. Postgrad Med J 2012; 88: 731 - 732

[3] Eng CM, Guffon N, Wilcox WR et al. Safety and efficacy of recombinant human alpha-galactosidase A-replacement therapy in Fabry's disease. N Engl J Med 2001; 345: 9-16

[4] Messalli G, Imbriaco M, Avitabile G et al. Role of cardiac MRI in evaluating patients with Anderson-Fabry disease: assessing cardiac effects of longterm enzyme replacement therapy. Radiol Med 2012; 117: 19-28

[5] Moon JC, Sachdev B, Elkington AG et al. Gadolinium enhanced cardiovascularmagnetic resonance in Anderson-Fabry disease: evidence for a disease specific abnormality of the myocardial interstitium. Eur Heart J 2003; 24: 2151e5

[6] Moon JC, Reed E, Sheppard MN et al. The histologic basis of late gadolinium enhancement cardiovascular magnetic resonance in hypertrophic cardiomyopathy. J Am Coll Cardiol 2004; 43: 2260-2264
[7] Reingold JS, McGavock JM, Kaka S et al. Determination of triglyceride in the human myocardium by magnetic resonance spectroscopy: reproducibility and sensitivity of the method. Am J Physiol Endocrinol Metab 2005; 289: E935-E939

[8] O'Connor RD, Xu J, Ewald GA et al. Intramyocardial triglyceride quantification by magnetic resonance spectroscopy: In vivo and ex vivo correlation in human subjects. Magn Reson Med 2011; 65: 1234-1238

[9] den Hollander JA, Evanochko WT, Pohost GM. Observation of cardiac lipids in humans by localized $1 \mathrm{H}$ magnetic resonance spectroscopic imaging. Magn Reson Med 1994; 32: 175- 180

[10] Petritsch B, Köstler H, Machann W et al. Non-invasive Determination of Myocardial Lipid Content in Fabry Disease by $1 \mathrm{H}$-MR Spectroscopy. Fortschr Röntgenstr 2012; 184: 1020-1025

[11] Petritsch B, Köstler H, Weng AM et al. Myocardial lipid content in Fabry disease: a combined $1 \mathrm{H}-\mathrm{MR}$ spectroscopy and MR imaging study at 3 Tesla. BMC Cardiovasc Disord 2016; 16: 205

[12] Sado DM, White SK, Piechnik SK et al. Identification and assessment of Anderson-Fabry Disease by Cardiovascular Magnetic Resonance Noncontrast myocardial T1 mapping clinical perspective. Circ Cardiovasc Imaging 2013; 6: 392-398

[13] Thompson RB, Chow K, Khan A et al. T1 mapping with cardiovascular MRI is highly sensitive for Fabry disease independent of hypertrophy and sex. Circ Cardiovasc Imaging 2013; 6: 637-645

[14] Arends M, Wijburg FA, Wanner $C$ et al. Favourable effect of early versus late start of enzyme replacement therapy on plasma globotriaosylsphingosine levels in men with classical Fabry disease. Mol Genet Metab 2017; $121: 157-161$

[15] Sueoka H, Ichihara J, Tsukimura T et al. Nano-LC-MS/MS for Quantification of Lyso-Gb3 and Its Analogues Reveals a Useful Biomarker for Fabry Disease. PLoS One 2015; 10: e0127048

[16] Lavoie P, Boutin M, Abaoui M et al. Fabry Disease Biomarkers: Analysis of Urinary Lyso-Gb3 and Seven Related Analogs Using Tandem Mass Spectrometry. Curr Protoc Hum Genet 2016; 90: 17.22.1 - 17.22.12

[17] Togawa T, Kodama T, Suzuki T et al. Plasma globotriaosylsphingosine as a biomarker of Fabry disease. Mol Genet Metab 2010; 100: 257-261

[18] Roller FC, Wiedenroth C, Breithecker A et al. Native T1 mapping and extracellular volume fraction measurement for assessment of right ventricular insertion point and septal fibrosis in chronic thromboembolic pulmonary hypertension. Eur Radiol 2017; 27: 1980 - 1991

[19] Messroghli DR, Radjenovic A, Kozerke S et al. Modified Look-Locker inversion recovery (MOLLI) for high resolution T1 mapping of the heart. Magn Reson Med 2004; 52: 141 - 146

[20] Tanislav C, Gündüz D, Liebetrau C et al. Cardiac Troponin I: A Valuable Biomarker Indicating the Cardiac Involvement in Fabry Disease. PLOS One 2016; 11: e0157640

[21] Rombach SM, Dekker N, Bouwman MG et al. Plasma globotriaosylsphingosine: diagnostic value and relation to clinical manifestations of Fabry disease. Biochim Biophys Acta 2010; 1802: 741 - 748

[22] Feustel A, Hahn A, Schneider $C$ et al. Continuous cardiac troponin I release in Fabry disease. PLoS One 2014; 9: e91757

[23] Kilinc G, Dogan OT, Berk S et al. Significance of serum cardiac troponin levels in pulmonary embolism. J Thorac Dis 2012; 4: 588-593

[24] Ries M, Clarke JT, Whybra C et al. Enzyme-replacement therapy with agalisade alfa in children with Fabry disease. Pediatrics 2006; 118: $924 \mathrm{e} 32$

[25] Germain DP, Waldek S, Banikazemi M et al. Sustained, long-term renal stabilization after 54 months of agalsidase beta therapy in patients with Fabry disease. J Am Soc Nephrol 2007; 18: 1547 - 1557

[26] Frustaci A, Morgante E, Russo MA et al. Pathology and function of conduction tissue in Fabry disease cardiomyopathy. Circ Arrhythm Electrophysiol 2015; 8: 799-805 